\title{
Laboreal
}

Volume $7 \mathrm{~N}^{\circ} 2$ | 2011

Varia

\section{Contributo para uma introdução ao estudo dos sistemas homens-máquinas}

Contribución a una introducción al estudio de los sistemas humanos-maquina

Contribution à une introduction aux études des systèmes hommes-machine

Contribution to an introduction to the study of man-machine systems

\section{Michel Olivier}

Tradutor. João Viana Jorge

\section{OpenEdition}

Journals

\section{Edição electrónica}

URL: http://journals.openedition.org/laboreal/7881

DOI: 10.4000/laboreal.7881

ISSN: 1646-5237

\section{Editora}

Universidade do Porto

\section{Refêrencia eletrónica}

Michel Olivier, «Contributo para uma introdução ao estudo dos sistemas homens-máquinas »,

Laboreal [Online], Volume $7 \mathrm{~N}^{\circ} 2$ | 2011, posto online no dia 01 novembro 2011, consultado o 24 setembro 2020. URL : http://journals.openedition.org/laboreal/7881 ; DOI : https://doi.org/10.4000/ laboreal.7881

Este documento foi criado de forma automática no dia 24 setembro 2020.

\section{(c) (†) \&)}

Laboreal está licenciado com uma Licença Creative Commons - Atribuição-NãoComercial 4.0 Internacional. 


\section{Contributo para uma introdução ao estudo dos sistemas homens- máquinas}

Contribución a una introducción al estudio de los sistemas humanos-maquina Contribution à une introduction aux études des systèmes hommes-machine Contribution to an introduction to the study of man-machine systems

\section{Michel Olivier}

Tradução : João Viana Jorge

\section{REFERÊNCIA}

Artigo original : Olivier, M. (1967). Contribution à une introduction aux études des systèmes hommes-machine. Bulletin du C.E.R.P., 1967-XVI-no1, p. 61-72.

1 É usual que uma introdução resulte de uma reflexão retrospectiva; que esta preceda a seguir o corpo do assunto deve-se a um simples artifício de apresentação. Proceder ao contrário é dar ao termo “ introdução » o seu sentido prospectivo, é traçar as grandes linhas de um edifício não com a presunção de um discurso pronunciado quando da colocação de uma primeira pedra, mas com a saudável desconfiança do construtor que recenseia os meios colocados à sua disposição. No caso dos estudos ditos “ de sistemas » a necessidade de um tal passo faz-se sentir tanto mais quanto os materiais e as ferramentas que deverão ser utilizadas aparecem excessivamente sedutores para não serem de todo suspeitos e que o terreno sobre o qual se deverá construir tem limites tão arbitrariamente fixados e é ocupado por tantas disciplinas (biologia, economia, psicologia, sociologia), que não podemos impedir-nos de pensar numa Babel. Seria oportuno, nesse contexto, recorrer a essa ascese que é a psicanálise do conhecimento objectivo recomendada por G. Bachelard e estudar desse ponto de vista a noção de 
sistema e conceitos aparentados. Todavia isso escapa ao domínio atribuído a uma introdução.

Para estudar um sistema, quer dizer um objecto demasiado grande ou demasiado complexo para permitir uma observação completa ou uma experimentação, utilizam-se concepções gerais sobre esse tipo de entidades como primeiro esboço de um modelo prático. Não é então destituído de interesse recordar como, há cerca de dez anos, o sociólogo americano P. Meadows (1957) introduzia uma exposição sobre este assunto : "Fica-se com a impressão, mesmo não sendo senão um leitor ocasional dos actuais trabalhos de pesquisa, que o termo " modelo " é o que há de mais fino na linguagem científica (...). Relacionado com o conceito de “sistema » e igualmente na moda, um “ modelo " tornou-se uma ferramenta potente e prestigiosa ». De facto uma revisão da literatura mostra que os diferentes modelos de sistemas relevam frequentemente quer da analogia vaga, mal definida ainda que por vezes poética, quer, por empréstimo da física de leis cuja aplicação ao domínio das ciências humanas requereria pelo menos uma certa prudência, quer de uma "matematização" refinada, aparentemente prematura se avaliada pelas dificuldades existentes em mostrar claramente o seu interesse. Se é indiscutível que uma formalização se torna indispensável para fornecer as bases teóricas suficientes para que se possam delas extrair aplicações, não é menos indiscutível que faltam, sobretudo neste domínio, descrições, morfológicas ou históricas, de sistemas, suficientemente coerentes para encarar essa formalização.

Poder-se-ia então perguntar se se alcança alguma utilidade na introdução da noção de sistema na análise dos conjuntos homem-máquina ou mais em geral na dos conjuntos tecnológicos complexos, produtos da transformação, pelo homem, do mundo natural e social. A ideia é a de que a ergonomia, a adaptação do trabalho ao homem, chegou a um ponto de saturação especulativa. Mais precisamente aparece que as soluções técnicas encontradas para os problemas do homem no trabalho pelos estudos da actividade motriz ou da tomada e tratamento da informação ou mesmo em alguns casos os estudos psico-sociológicos, são essencialmente limitados no tempo porque a evolução industrial os torna muito rapidamente efémeros e no espaço porque se percebe rapidamente que se se melhorou uma malha da rede, uma tensão prejudicial à integridade desta subsiste permanentemente. Isto não significa todavia que se tenha chegado a uma saturação quanto à extensão desses estudos - pelo menos a médio prazo isso não se põe em causa - mas sim que esta situação exige ultrapassagem e esforços de adaptação. Parece mesmo haver nesta eflorescência de trabalhos empreendidos sobre o assunto qualquer coisa de aproveitável e que a combinação da ideia de sistema com os problemas que coloca a integração de homens nos conjuntos tecnológicos complexos engendrou um frutuoso domínio de pesquisas permitindo aquela ultrapassagem.

4 Considere-se pois o que aqui vai ser exposto como o balanço provisório e parcial de uma aquisição mais colectiva do que individual, como o posicionamento dos elementos de um problema e mais ainda como uma tentativa de interligar entre eles diferentes conceitos e um esforço de elaboração de um sistema. 


\section{Apresentação esquemática das diversas concepções do estudo de sistemas}

5 Antes do mais trata-se de gizar um rápido quadro histórico dos diversos “movimentos » de estudo de sistemas, pertinentes para a questão, para recolocar no seu quadro geral a análise dos sistemas homem-máquina.

\section{A teoria geral dos sistemas}

6 O movimento da "general systems theory" nasceu - tanto quanto se pode falar de nascimento ex nihilo - no fim do intervalo entre as duas guerras, em Viena, dos trabalhos do biólogo e filósofo L. von Bertalanffy cujo conteúdo se manteve por publicar ou pouco divulgado até ao fim da segunda guerra mundial [L. von Bertalanffy $(1945,1949)]$.

7 Teórico das concepções organicistas em biologia, L. von Bertalanffy (1950a) expandiu naturalmente as suas ideias de uma gestalt orgânica, a uma teoria geral dos sistemas que deveria promover a unidade da ciência, unidade essa baseada na estrutura isomórfica das leis dos diferentes ramos daquela. Que esse movimento tenha a sua origem nas mesmas tendências que as que presidiram à eclosão da teoria da Gestalt é inegável; aí se reencontram o mesmo anti-mecanicismo, o mesmo anti-atomismo, o mesmo esquema de hilemorfismo [ $\left.{ }^{1}\right]$ do naturalismo alemão, os mesmos princípios de totalidade, de organização, de interacção dinâmica. Não se podem igualmente impedir as aproximações das concepções de L. von Bertalanffy às de K. Goldstein (1934). A sua consideração das analogias nos diferentes domínios da ciência tem raízes na fenomenologia física de E. Mach (1910).

8 A reunião em torno das suas ideias de autores com horizontes tão diversos como A. Rapoport, D. Krech, R. W. Gérard, por exemplo, após a sua instalação além atlântico (Canada, 1949 ; USA, 1954) e o apogeu das suas concepções na fundação da Society for the Advancement of General Systems Theory em 1954 e depois na publicação anual a partir de 1956 de "General Systems" de que é co-editor com A. Rapoport, não deve esconder que se está ainda bem longe de uma teoria geral dos sistemas e é forçoso admitir que de momento somente existem estudos de sistemas empreendidos sob uma ou outra óptica. Para dar conta da teoria de L. von Bertalanffy seria ocioso acrescentarlhe as reformulações que foram propostas ou as críticas tecidas; é satisfatório mencionar brevemente alguns dos seus aspectos mais centrais. Um sistema, conjunto de elementos em interacção, pode ser representado abstractamente por um sistema de equações diferenciais contendo o tempo como variável independente ; a introdução de condições específicas respeitantes aos parâmetros e as variáveis que lá figuram permite mostrar o isomorfismo estrutural entre diversos fenómenos biológicos, físicos, económicos ou outros. Serve além disso para ilustrar mais adequadamente certas características dos sistemas orgânicos. Em primeiro lugar a consideração de dois casos extremos, um em que a variação de cada variável depende unicamente da mesma e outro em que a variação de cada uma das variáveis determina uma variação de todas as outras afectando portanto o conjunto do sistema, permite opor a hipótese mecanicista de independência entre os elementos cuja soma das variações dá a do conjunto global, o que justifica em direito o estudo de partes isoladas, e a hipótese gestaltista em que o sistema é encarado como um todo no interior do qual cada elemento não tem sentido 
nem existência senão graças à sua interacção com os outros. Em segundo lugar pode assim caracterizar-se o devir de um organismo pela segregação ou mecanização progressiva, quer dizer o decréscimo, com o tempo, da interacção entre os elementos e o seu arranjo em subsistemas subordinados, implicando um acréscimo da complexidade do sistema e uma regulação cada vez mais difícil. Esta segregação progressiva é compensada por uma centralização progressiva, dependendo a evolução do tempo de um elemento central. É somente ao nível dos sistemas altamente mecanizados subdivididos em subconjuntos especializados, que um estudo analítico pode ser empreendido.

9 L. von Bertalanffy introduz então as noções de sistema aberto e de equilíbrio dinâmico, tomadas de empréstimo à termodinâmica dos fenómenos irreversíveis, que lhe fornecem a interpretação de outras características dos sistemas orgânicos. Um sistema diz-se aberto quando há troca de matéria com o exterior, e um equilíbrio dinâmico é o estado de um sistema no qual todas as variáveis macroscópicas se mantêm constantes ainda que subsistam variações no processo de fluxo das substâncias. No caso dos fenómenos vitais este estado de equilíbrio dinâmico é equifinal, é independente das condições iniciais, quer dizer, pode ser alcançado a partir de estados diferentes e por vias diferentes visto ser exclusivamente determinado pelos parâmetros do sistema e do processo de troca de substâncias com o exterior. A equifinalidade é responsável pelas regulações primárias dos sistemas orgânicos e é progressivamente restringida pela subdivisão do sistema em partes separadas. Noutros termos, pode dizer-se que há manutenção dinâmica da estrutura diferenciada do organismo no seio de um meio exterior menos organizado e que esta é conseguida equifinalmente.

\section{A teoria dos sistemas auto-organizados}

10 Uma outra via de abordagem à teoria dos sistemas é a da cibernética, mais precisamente com o formato que lhe deu W. R. Ashby (1956). Este segundo movimento, de que se podem citar como outros representantes S. Beer, e G. Pask, por exemplo, se estabeleceu de tempos a tempos, aliás com muitas reticências, contactos com o primeiro, baseando-se nos primeiros textos de W. R. Ashby (1947) reivindica uma parte importante da teoria dos sistemas introduzindo o conceito de auto-organização [M. C. Yovits e S. Cameron (1960) ; H. Von Foester e G. W. Zopf (1962)].

11 Sabe-se que a cibernética estuda a direcção dos sistemas dinâmicos complexos compostos por subsistemas mais simples inter-reagentes cujo estado é caracterizado pelos valores dos parâmetros e das derivadas em relação ao tempo dos elementos componentes. Ocupa-se portanto, em particular, da acção exercida sobre esses parâmetros, acção que modifica o processo ou passagem de um estado a um outro. Deve considerar-se que os problemas de controlo e de comunicação que acentua não constituem senão um aspecto parcial do estudo de sistemas sendo somente quando introduz a noção de organização, de estrutura, que se situa no seu quadro mais geral.

Neste contexto, o sistema pode ser estudado quer como um todo indivisível, uma caixa preta, analisando os seus estados de entrada e de saída, quer como um conjunto composto de partes funcionais definindo o seu estado. Se se especifica o conjunto $\mathrm{S}$ dos estados do sistema, o conjunto I dos estados da envolvente ou entrada e se $\mathrm{S}$ é o produto cartesiano $\pi T_{i} T_{i}$ onde cada parte $i$ é caracterizada pelo conjunto dos estados $T_{i}$ a organização entre elas é definida pela aplicação $f$ do produto I x S em S [W. R. Ashby 
(1961)]. Há portanto a definição de uma relação, de um arranjo de estruturas que controlam ou dirigem o processo de forma que este alcance um determinado objectivo.

O conceito de auto-organização refere-se a uma capacidade de mudança qualitativa do sistema quando este não mais consegue fazer face a uma perturbação, ao que W. R. Ashby chama a ultra-estabilidade. Numa óptica mais global há uma multi-estabilidade, ajustamento ao meio por um ou outro dos sistemas ultra-estáveis. A auto-organização pode ser encarada segundo duas acepções bem diferentes: seja como passagem do desorganizado ao organizado ou do menos organizado ao mais organizado, o reforço da estrutura ou a criação de novas relações, seja como a passagem de uma má organização a uma melhor organização dada a relação entre um conjunto de perturbações exteriores e a finalidade do sistema. No primeiro caso, encarado por exemplo por G. Pask (1959) estamos perante o inverso de uma segregação progressiva, o que poderia chamar-se uma sistematização ou concretização, o crescimento, com o tempo, da interacção entre os elementos ; no segundo caso, tratado inicialmente por W. R. Ashby, há uma adaptação por tentativa e erro, quer dizer que a partir de um certo nível crítico se dá um salto nas características do sistema que modifica o processo anterior e isto iterativamente, de modo a restabelecer um comportamento adequado. Nesta última acepção nenhuma máquina, no sentido que W. R. Ashby lhe dá, é auto-organizadora, a passagem de uma má organização a uma boa organização é devida a um agente exterior acoplado com o sistema e não pode ser proveniente de uma causa interior. De facto o modelo é aqui o de um "cérebro" mas sem menção a uma aprendizagem, sem modificação das estruturas através da experiência. Tudo se passa como se o sistema, reagindo à perturbação actual, se transformasse num outro sistema. É neste sentido que outros autores procuraram desenvolver o conceito de auto-organização atacando sob ângulos diversos o problema de um sistema que constrói um reflexo interno da envolvente, a melhora e a utiliza. Assim, por exemplo S. Beer (1961) propõe uma teoria do funcionamento de um "cérebro" capaz de organizar, de controlar e de fazer evoluir um sistema industrial. É também a razão pela qual se vêem os simpósios sobre sistemas com auto-regulação acolher os especialistas dos mecanismos de aprendizagem dos autómatos, da biologia do cérebro, da lógica dos neurónios, das máquinas heurísticas ...

\section{A tecnologia dos sistemas}

13 A "systems engineering", essa, nasceu das crescentes solicitações da tecnologia moderna e da experiência com os problemas dos sistemas militares complexos adquirida durante a última guerra mundial. Com a ausência de preconceitos dos tecnocratas os praticantes da systems engineering favorecem com o mesmo acolhimento as duas tendências antes citadas esperando que das concepções "filosóficas" daqueles teóricos possa emergir alguma possibilidade de aplicação [D. P. Eckman (1961) ; M. D. Mesarovic (1964)].

De facto é relativamente desajeitado circunscrever o campo de actividade do engenheiro de sistemas que tendo em vista a análise ou a síntese dum conjunto técnico utiliza simultaneamente os métodos da pesquisa operacional e os procedimentos modernos de controlo automatizado. Se se define o processo de um sistema como uma sequência de operações ou de acções que transformam certas quantidades (entradas) em outras (saídas) sobressai que o objectivo da systems engineering é a maximização ou minimização de um determinado valor das saídas como a eficácia ou o custo. Por outro 
lado um sistema pode ser encarado como tendo um certo número de objectivos cuja ponderação difere de um sistema para outro. A finalidade do engenheiro de sistemas é então a de optimizar as funções do conjunto de acordo com os diferentes pesos atribuídos aos objectivos [J. A. Morton (1959)].

Estas duas perspectivas da tecnologia de sistemas que intitularemos respectivamente de operatória e funcional estão sempre intimamente entrelaçadas e de um modo mais global pode dizer-se que o problema fundamental é o do controlo e da optimização do desempenho do sistema. Um primeiro aspecto importante da systems engineering é, além da amplificação das técnicas tradicionais da pesquisa operatória, a definição de duas características dos conjuntos técnicos complexos referentes à sua operacionalidade (availability) : a fiabilidade (reliability) da qual um indicador é a frequência das avarias, dos incidentes, dos disfuncionamentos - sendo as principais funções do sistema que contribuem para a sua realização a manutenção preventiva (avarias por desgaste) e o controlo antes da entrada em serviço (avarias de rodagem) - e que coloca ao nível do processo o problema da estruturação das relações qualitativas entre a fiabilidade dos componentes para assegurar a do conjunto; a recuperabilidade (mantainability) de que um indicador é o tempo de reparação, de retoma do funcionamento normal tanto melhor quanto as disposições existentes para essa retoma sejam mais eficazes, quer dizer os disfuncionamentos são detectados, localizados e rapidamente corrigidos (controlo, manutenção correctiva, aprovisionamento em peças de substituição, check-lists). Esta distinção entre "reliability" e "mantainability" nem sempre é tão clara na literatura, existindo uma ligação estreita entre estes dois parâmetros que caracterizam a sobrevivência do sistema [R. E. Barlow e F. Proschan (1965), A. S. Goldman e T. B. Slattery (1964)].

16 Em particular a noção de sistema auto-recuperável ou auto-reparável salienta bem esta dificuldade em distinguir entre um sistema cuja fiabilidade é aumentada pela introdução de uma redundância, duma duplicação de componentes (ou de uma sua pluri-funcionalidade) e um outro cuja recuperabilidade é aumentada pelo recurso a elementos de socorro requerendo dispositivos de detecção de avarias e de comutação entre órgão principal e órgão auxiliar.

17 Um segundo aspecto importante da systems engineering deve-se ao desenvolvimento das teorias sobre o controlo nomeadamente à tomada em consideração dos problemas colocados pelos sistemas não lineares, pelos sistemas complexos com múltiplas variáveis e pelo controlo adaptativo. É em particular este último domínio que se apresenta como detentor de mais possibilidades de influenciar o futuro da ergonomia dos processos industriais. Tal como já se propôs uma análise do trabalho do homem interveniente naqueles em termos de modelo de regulação simples [J. M. Faverge e col. (1966)], parece certo que nesse quadro se venha a estudar cada vez mais o trabalho do operador humano sob a perspectiva da teoria dos sistemas de controlo adaptativo ou optimizado que se ajustam a um resultado expresso por meio de um índice de desempenho, optimizando os seus parâmetros ou a sua estrutura em resposta a uma variação do sinal de entrada ou a uma alteração espontânea do sistema [K. P. Timpe (1966)]. Não é destituído de interesse fazer notar a diferença entre um sistema com controlo adaptativo e um outro com auto-organização : no primeiro caso a adaptação é transitória o que implica em particular que toda a informação necessária ao reconhecimento das perturbações e ao programa de resposta deve estar incluído no 
sistema ; no segundo ela é permanente, há um dispositivo de aprendizagem adaptativa, sendo a experiência própria do sistema que actua e não a do seu construtor.

\section{Características muito gerais de um sistema e particularização dos sistemas homem-máquina.}

18 A noção de sistema tal como emerge desta apresentação, necessariamente breve e incompleta, especialmente dos trabalhos de L. von Bertalanffy e de W. R. Ashby e doutros teóricos dos sistemas, é a de um esquema visando uma descrição universal homogénea.

19 No caso de que tratamos, o dos conjuntos tecnológicos complexos, pareceria que a ambição devia ser menor e que nos poderíamos contentar com um esquema mais específico e relativamente autónomo como o da systems engineering. Todavia impõe-se um certo recuo se se pretende que o modelo se aplique em extensão ao amplo contexto de conjuntos englobando homens, grupos sociais, calculadoras, máquinas e equipamentos automatizados. Por outro lado se se admite que pela sua génese cada sistema é único e particular, isso implica que os termos e os conceitos utilizados deverão aplicar-se a cada caso. As condições de uma síntese enunciar-se-iam portanto da seguinte forma: postos em presença de modelos mais ou menos específicos e inconsistentes entre eles,

- pode-se considerá-los como representando uma parte do modelo geral a elaborar e conseguir colocar-se a um nível de reformulação que tenha em conta o maior número dos seus aspectos coerentes, o que deixa a porta aberta a uma extensão da teoria mas não a modificações da mesma [(J. D. Miller (1965)] ;

- podemos colocar-nos num plano suficientemente abstracto para ter em conta os aspectos mais centrais desses modelos mas perde-se em informação o que se ganha em possibilidades de reestruturação [M. D. Mesarovic (1963)].

Colocar-nos-emos mais próximos do primeiro caso permitindo assim certas interpretações verbais mas tomaremos todavia como ponto de partida o nível de generalidade do segundo caso baseando-nos principalmente nos desenvolvimentos devidos a M. D. Mesarovic.

\section{Definição de um sistema}

O princípio básico da noção de sistema é o das relações entre os objectos componentes de um conjunto o que faz com que este seja considerado como uma entidade e não como uma " soma » de elementos heterogéneos. Considere-se uma família de conjuntos $\mathrm{X}_{1}, \mathrm{X}_{2}, \ldots \mathrm{X}_{\mathrm{j}}, \ldots \mathrm{X}_{\mathrm{n}}$, cada conjunto caracterizando um objecto ; um sistema é uma relação $R=\left\{R_{1}, R_{2}, \ldots R_{j}\right\}$ definida pelo produto cartesiano $X=\pi_{j} X_{j}$ dessa família de conjuntos. A introdução de um procedimento que permite definir indutivamente os termos $X_{j}$ e $R_{j}$ especifica completamente o sistema. Para um dado conjunto de objectos as relações consideradas dependem do ponto de vista em que nos coloquemos. Esta definição pode parecer geral e abstracta todavia veremos que fornece os meios para enunciar mais estritamente diferentes modalidades de estudo de conjuntos tecnológicos complexos porque tem a vantagem de permitir a referência a uma classe de modelos em que a interacção é formalmente determinada. 


\section{Limites de um sistema} exterior E é uma questão puramente convencional, podendo sempre alargar-se o domínio do estudo admitindo que um outro sistema $S^{\prime}$ engloba S. Dir-se-á que S é um subsistema de $\mathrm{S}^{\prime}$. O sistema $\mathrm{S}^{\prime}$ é a união de $\mathrm{S}$ com uma parte de E. Nesse sentido é preciso fazer notar que a distinção entre sistema aberto e sistema fechado é puramente teórica, pelo menos no que nos diz respeito. Um conjunto tecnológico complexo é aberto porque no estudo que dele fazemos negligenciamos um certo número de componentes emitindo por exemplo a hipótese de um certo amortecimento devido ao afastamento de influências exercidas sobre o sistema. Todavia o facto de haver incerteza neste sistema incompleto coloca com acuidade o problema da decisão e do controlo.

\section{Reticulação do sistema em componentes}

Tal como se pôde delimitar exterior e sistema pode subdividir-se este último em subsistemas. Não para isolar artificialmente um deles e submetê-lo a estudo mas para analisar as suas interacções. Se a dicotomia sistema-exterior é habitualmente feita $a$ priori, o mesmo não acontece com a reticulação do sistema escolhido e torna-se então útil atribuir limites às nossas tendências reducionistas, definir portanto as componentes primordiais de um sistema.

Considerando um sistema caracterizado por uma relação de ordem $n, R\left(X_{1}, \ldots X j, \ldots X n\right)$, o procedimento geral de reticulação consiste em encontrar duas novas relações $R_{1}$ e $R_{2}$ de que R seja o produto relativo quer dizer satisfazendo a condição :

$(x \mathrm{R} y) \leftrightarrow\left[\left(x \mathrm{R}_{1} z\right) \Lambda\left(z \mathrm{R}_{2} y\right)\right]$

$\mathrm{R}_{1}\left[\mathrm{X}_{1}, \ldots \mathrm{X}_{\mathrm{j}}, \ldots \mathrm{Z}\right]$ e $\mathrm{R}_{2}\left[\mathrm{Z}, \mathrm{X}_{\mathrm{j}+1}, \ldots \mathrm{X}_{\mathrm{n}}\right]$

M. D. Mesarovic (1963) mostra que um sistema de ordem $n$ não pode em geral ser decomposto em subsistemas de uma ordem inferior a 3. Em particular, no contexto dos sistemas dinâmicos (em que os elementos dos $\mathrm{X}_{\mathrm{j}}$ são funções do tempo), uma aplicação desse teorema é a definição de uma máquina (no sentido que lhe dá Ashby) cujos estados, interno e do exterior determinam unicamente o estado seguinte. Uma componente primordial do sistema será representada por uma relação entre três termos, a produção de uma saída a partir de duas entradas, uma caracterizando a acção do exterior e outra a operação.

\section{Estrutura operatória e estrutura funcional}

A relação $\mathrm{R}$ definidora de um sistema pode ser considerada como um exemplo específico de uma relação mais abstracta que nos dê a estrutura do sistema. Mais 
precisamente distinguir-se-ão duas vias de estudo das estruturas de um conjunto tecnológico complexo :

a. A análise da estrutura operatória do sistema em que se descreverá um conjunto de causas e de efeitos em termos de relações entradas-saídas entre componentes situa-se então ao nível do processo de um sistema.

b. A análise da estrutura funcional em que se descreverão as actividades do sistema e das suas partes na base de interacções entre subsistemas em termos da prossecução de uma dada finalidade, de um programa. Esta distinção recobre a de M.D. Mesarovic e D. P. Eckman (1961) entre abordagem " causal » e abordagem " teleológica ».

29 Comummente dispõe-se de suficiente informação sobre um conjunto tecnológico para obter determinadas medidas de variáveis do interior do próprio sistema. De modo simples encarar-se-á então a sua estrutura ou sob o ponto de vista a) de montagens de componentes em série, quer dizer tais que a saída de uma serve de entrada em outra ou b) de montagens de componentes em paralelo, isto é, dispostas de tal modo que cada uma contribui para uma saída comum. Trata-se da estruturação mais natural do processo de um sistema: para um subsistema em série a avaria de uma das componentes arrasta a do conjunto, o que se remedeia com um subsistema de redundância em paralelo, remetendo todavia nos dois casos para leis simples entre as fiabilidades das componentes; numa representação por diagramas de blocos das funções de transferência de um processo podem combinar-se os passos paralelos e uma relação simples liga as transmitâncias dos blocos em série ; para encontrar uma solução para os gargalos de estrangulamento tem de resolver-se um problema de filas de espera em cascata ou múltiplas ...

30 Para fazer aparecer a estrutura funcional de um conjunto tecnológico partir-se-á de um outro ponto de vista menos físico a que o psicólogo ou o engenheiro de organização está mais acostumado. Traçar-se-ão determinadas linhas de clivagem, certas categorias na globalidade do comportamento do sistema serão apercebidas. Como faz notar excelentemente M. Merleau-Ponty (1942) " as estruturas às quais assim acedemos, não são, como as do organismo, nem causas suplementares que orientariam os fenómenos parcelares, nem simples nomes para as designar, mas ideias nas quais participam sem as conter ». O sistema comporta-se como um todo de tal modo que se deve introduzir a noção de função pelo desvio da atribuição de um significado comum a várias manifestações de actividade das partes do sistema. Quando se analisa por exemplo a interacção entre a função de produção e a de prevenção [J. M. Faverge (1967)] o objectivo é alcançar uma certa compreensão dos comportamentos do homem, unidade funcional da organização. Este aspecto do estudo dos sistemas homem-máquina aparece actualmente como predominante, aliás quaisquer que sejam as orientações particulares dadas às pesquisas: compare-se por exemplo o que sobre isso dizem R. M. Gagné (1962) :

31 "Qualquer sistema razoavelmente pouco complexo que seja requer uma interacção real entre o homem e as outras partes do sistema que podem ser máquinas, outros homens ou uma combinação de ambos. Deve portanto encontrar-se um modo de pensar aplicável às funções das máquinas e às funções do homem no interior de um quadro que torne possível relacionar estes dois tipos de funções e de objectivos comuns, quer dizer os objectivos do sistema » e D. I. Iordansky (1965) “os homens, os equipamentos automatizados, as máquinas, que são os elementos dos grandes sistemas constituem em condições reais as estruturas complexas e específicas cujo estudo apresenta, sob 
qualquer perspectiva, um interesse considerável (...)» e mais adiante caracteriza este tipo de pesquisa onde se preocupa com "o aspecto estático e dinâmico das estruturas funcionais e hierárquicas das colectividades dos grandes sistemas (...), com os aspectos dinâmicos das aç̧ões recíprocas entre os elementos, homens e máquinas, das relações mútuas entre os membros das colectividades no interior dos subsistemas e entre as colectividades dos diferentes subsistemas, entre superiores e subordinados (...) ».

32 A componente primordial da organização de um sistema, do conjunto das interacções entre as diversas funções deste será igualmente representada por uma relação entre três termos, actuando a produção de uma saída na unidade operatória a partir de duas entradas, uma conduzindo a informação desta última, a outra caracterizando o " seu programa ", o seu " objectivo » [" goal-seeking unit » de M. D. Mesarovic e D. P. Eckman (1961)]. Notemos que uma unidade funcional ou célula pode ser um elemento regulador, humano ou mecânico, e neste segundo caso considerar-se-á como fazendo parte do que designamos como o processo.

\section{Estrutura e história}

33 É evidente que a utilização do conceito de estrutura inclui o tempo como condição de definição. A identificação da estrutura de um sistema depende da existência de ligações relativamente estáveis entre os elementos num dado intervalo de tempo. A história do sistema seria então a história da sua estrutura, a pluralidade das rupturas do equilíbrio, das modificações do processo, da passagem de uma organização a outra.

Dispõe-se de poucos estudos sobre a evolução histórica dos sistemas tecnológicos complexos, ou melhor, eles existem muito sob um ou outro aspecto, técnico por exemplo [citemos neste quadro a muito boa tese de G. Simondon (1958)], ou económico, mas não sob o duplo ponto de vista da evolução conjugada da estrutura operatória e da estrutura funcional de um conjunto tecnológico. É portanto difícil dar uma panorâmica dos modelos históricos do estudo dos sistemas homem-máquina, mas entretanto na linha de pensamento já adoptada definir-se-ão duas características dos sistemas adaptáveis e portanto incluídos por isso mesmo na corrente da história, a flexibilidade e a mutabilidade.

35 A mutabilidade é aquela qualidade da estrutura funcional de um sistema aberto à envolvente e portanto receptivo à pressão desta, que aceita tomar decisões na incerteza criada pelas zonas marginais existentes entre ele e o meio exterior [J. M. Faverge (1966b)]. A tradução desta mutabilidade na estrutura operatória é a flexibilidade, qualidade do processo de um sistema para o qual as unidades funcionais previram, em certa medida para as facilitar, alterações ulteriores podendo intervir na sequência de flutuações tanto económicas como tecnológicas.

\section{O sistema homens-máquinas}

Na perspectiva da ergonomia dos sistemas homens-máquinas a relação causal recíproca, de implicação mútua, que agrega o processo tecnológico, o conjunto das relações entradas/saídas entre unidades operatórias e o seu inventor, o homem, não pode ficar mal conhecida ; seria arbitrário separar a realidade humana cristalizada nas estruturas operatórias (o que de forma mediata permite reconhecer-lhe as funções) e as 
unidades funcionais criadoras e organizadoras, os homens que lhe asseguram a sobrevivência pelo controlo, a manutenção, a coordenação, a adaptação.

Momento da análise de um sistema, a estrutura operatória não é senão uma abstracção destacada do seu aparelho funcional, um dado imediato que facilita a representação.

o homem deve ser visto seja como componente do processo, e como portador de ferramentas, e desempenha então um papel inferior ao da individualidade técnica (a evolução tecnológica tende a desembaraçá-lo dele), quer como elemento da organização da estrutura funcional do conjunto e desempenha então um papel superior ao da individualidade técnica [G. Simondon (1958)]. Nesta linha de pensamento é legítimo pretender que é por o homem ter concebido as máquinas a partir das suas próprias funções que num movimento inverso viu um modelo da sua actividade nesta materialização ; a máquina não seria um modelo do homem senão por que o homem a fez à sua imagem. $\mathrm{O}$ mesmo princípio de reciprocidade fez-lhe perceber, através da estrutura funcional de um sistema, um organismo vivo [J. M. Faverge (1966b)].

Estamos agora em posição de circunscrever o domínio das pesquisas em sistemas homens-máquinas ; será o estudo da conjunção da estrutura operatória e da estrutura funcional através de características globais do desempenho do sistema tais como a estabilidade, a fiabilidade, a recuperabilidade, e de características globais da sua adaptação estrutural tais como a flexibilidade e a mutabilidade, o que levará, em particular, ao interesse pela interacção entre o nível da organização e o nível do processo.

\section{BIBLIOGRAFIA}

Ashby, W.R. (1947). - Principles of the self-organizing dynamic system. J. Gen. Psych, 37, 125-128.

Ashby, W.R. (1956). - An introduction to Cybernetics, Londres, Chapman and Hall.

Ashby, W.R. (1961). - Principles of the self-organizing system, in Principles of Self-Organizing system, Von Foerster H. et Zopt G. W. (eds) (1962), 255-278.

Beer, S. (1961). - Toward the cybernetic factory, in Principles of Self-Organization, Von Foerster H. et Zopt, G W. (eds), 1962, 25-80.

Barlow, R. E. et Proschan, F. (1965). - Mathematical theory of reliability, Wiley, New York.

Eckman, D.P. (ed.) (1961). - Systems Research and Design, Proc. Ist. Syst. Symp. Case Inst. Techn. 160 , Wiley.

Faverge, J. M. et coll. (1966a). - Lérgonomie des processus industriels. Ed. Inst. Sociol., Univ. Libre de Bruxelles.

Faverge, J.M. (1966b). - L'organizzazione viva. Riv. Psi. Lav., 4, 39-56.

Faverge, J.M. (1967). - Une analyse fonctionnelle dualiste des activités des cellules d'un système ; á paraitre dans la Revue Philosophique. 
Gagne, R. M. (1962). - Human functions in systems, in Psychological Principles in system Development. Gagne R. M. (ed.). Holt, p. 65.

Goldman, A.S. et Slattery, T.B. (1964). - Maintainability : a major element of system affectiveness., New York, Wiley.

Goldstein, K. (1934). - Der Aufbau des organismus. M. Nijhoff, La Haye.

Iordansky, D.I.(1963). - Nékotoryé zadatchi issledovania kollektinov lioudei, outchastvouiouchtchikh v oupravlévij bolchimi sistemami. In Sistema tchelovek i avtomat D.A. Ochanine (red), Naouka, Moscou, 1965, 20-27.

Mach, E. (1910). - Ueber das Prinzip der Vergleichung in der Physik. Popular-Wissen-schafiliche Vorlesungen, Leipzing.

Meadows, P., (1957). - Models, systems and science. Amer. Soc. Rev., 22, 3.

Merleau-Ponty, M. (1942). - La struture du comportement. P.U.F., 206.

Mesarovic, M.D. et Eckman, D.P.(1961). - On some basic concepts of General Systems Theory, Pro IIId Int. Cong. Cybern., Namur, Ass. Int. Cybern., 1963.

Mesarovic, M.D. (1963). - Foundations for a General System Theory, in Views on General Systems Theory. Mesarovic M.D. (ed.), 1964, 1-24.

Mesarovic, M.D. (ed.) (1964). - Views on General Systems Theory. Proc. II d Systems Sump., Case Inst. Techn., 1963, New York, Willey.

Miller, J. G. (1965). - Living systems : Basic Concepts, Structure and Process, Cross Level Hypothesis. Behaw. Sc., 10, 3 et 4, 193-237 et 334-411.

Morton, J.A. (1959). - Integration of Systems Engineering with Component development Eleclr. Manuf., 64, 85.

Pask, G. (1959). - The natural history of Networks in Self-Organizing Systems, Yovits M.G. et Cameron S. (eds) (1959).

Simondon, G. (1958). - Du monde d'existence des objets techniques. Aubier.

Timpe, K. P. (1966). - Critères d'optimisation dans le système homme-machine. Act. XVIII. Cong. Int Psych., Moscou.

Von Bertalanffy, L. (1945). - Zu einer allgemeinen systemlehre, BI. Deutsche Philos., 18, repau dans Biologia Generalis, 19, 1949, 114-129.

Von Bertalanffy, L. (1949). - Das Biologische Weltbild, A. Francke, Berne.

Von Bertalanffy, L. (1950a). - An outline of General System Theory. Br. J. Philos. Sci., 1, 134-165.

Von Bertalanffy, L. (1959b). - The theory of open systems in physics and biology Science, 111, 23-29.

Von Foerster, H. et Zopf, G.W. (eds) (1962). - Principles of Self-organization. Trans. Univ. Illinois. Symposium on self-Organization, 1961, Pergamon Press.

Yovits, M. C. et Cameron, S. (eds) (1960). - Self-Organizing Systems, Interdisciplinary Conf. Illinois, 1959, Pergamon Press. 


\section{NOTAS}

1. Teoria que remonta a Aristóteles segundo a qual os corpos eram constituídos por dois princípios: forma e substância.

\section{RESUMOS}

A rapidez do progresso técnico e a grandiosidade dos conjuntos tecnológicos actuais exigem do ergónomo um esforço de ultrapassagem do tradicional estudo de posto limitado no espaço e no tempo. Nesta perspectiva parece que seria interessante introduzir a noção de "sistema-homemmáquina » e para isso utilizar o contributo conceptual dos movimentos de estudo de sistemas : teoria geral dos sistemas, teorias dos sistemas auto-organizados e tecnologia dos sistemas. Após uma apreciação sumária dos mesmos o autor evoca algumas características muito gerais de um sistema e tenta a seguir circunscrever o domínio da pesquisa sobre os sistemas homem-máquina em particular graças à distinção entre o nível do processo e o nível da organização de um sistema.

La rapidez del progreso técnico y el tamaño de los conjuntos tecnológicos actuales exigen que el ergónomo se esfuerce por superar estudios tradicionales del puesto que se limitan en el tiempo y el espacio. Desde esta perspectiva, pareciera ser interesante introducir la noción de "sistemas hombre-máquina" y para ello utilizar el aporte conceptual del movimiento de estudio de sistemas : teoría general de sistemas, teorías de sistemas de auto-organización y tecnología de sistemas. Tras una revisión esquemática de estos, el autor presenta las características generales de un sistema e intenta circunscribir el ámbito particular de las investigaciones sobre sistemas hombre-máquina mediante la distinción del nivel de proceso y del nivel de organización de un sistema.

La rapidité du progrès technique et la grandeur des ensembles technologiques actuels exigent de l'ergonome un effort de dépassement de la traditionnelle étude de poste limitée dans le temps et dans l'espace. Dans cette perspective, il semble qu'il y aurait intérêt à introduire la notion de “système-hommes-machines » et pour cela utiliser l'apport conceptuel des mouvements d'étude de systèmes: théorie générale des systèmes, théories des systèmes auto-organisation et technologie des systèmes. Après un aperçu schématique de ceux-ci l'auteur envisage quelques caractéristiques très générales d'un système et tente ensuite de circonscrire le domaine de recherches sur les systèmes hommes-machines en particulier grâce à la distinction entre le niveau du processus et le niveau de l'organisation d'un système.

The speed of technical progress and the size of the present technological systems require from the ergonomist an effort to go beyond the traditional job analysis, limited in time and space. From this view point it should be interesting to bring in the concept of "man-machine systems" and to use for this purpose the conceptual contributions of the different branches of study that deal with systems: general systems theory, theory of self-organizing systems and systems engineering. After a schematic description of these contributions the author first examines some very general characteristics of a system and tries to limit the field research about man-machine systems, especially by making a distinction between the process level and thee organizations level of a system. 


\section{AUTORES}

MICHEL OLIVIER

Laboratoire de Psychologie de l'Université Libre de Bruxelles 